\title{
Normal labor curve is affected by fetus gender: A cohort study
}

\author{
Mandana Rashidi Meibodi ${ }^{1}$, Elaheh Mossayebi ${ }^{2}$, Zahra Najmi ${ }^{3}$, Yousef Moradi ${ }^{4}$, \\ Azadeh Afzalzadeh ${ }^{2 *}$
}

\section{Abstract}

Background: Fetal male gender may affect the progression of labor and could be a risk factor for labor arrest. This study was conducted to evaluate the effect of fetus gender on labor curve.

Methods: In this cohort study, 1550 singleton term pregnant women in labor phase (either spontaneous or by induction) were enrolled. Results of regular cervical examination, dilation, length of labor stages, mode of delivery, and sex of the fetus, and birth weight were recorded for all participants. Labor progression curve was compared between two sex groups with independent $\mathrm{t}$ test and chi2 test.

Results: Finally, 1527 women completed the study (47.8\% female and 52.1\% male). Mean duration from beginning of the active phase up to full dilatation, from 4 to $6 \mathrm{~cm}, 6$ to $8 \mathrm{~cm}$, and 8 to $10 \mathrm{~cm}$ dilatations, were significantly longer in the male sex group compared to the female $(\mathrm{p}<0.05)$. All durations were also significantly different when parity was considered $(\mathrm{p}<0.05)$. We could not show fetal sex as an independent risk factor for active phase arrest (OR Adjusted: 1.18, CI 95\% 1.01:1.42).

Conclusion: Active phase stage was slower and longer in women who carried male fetuses compared to those carrying female fetuses; however, fetal sex did not increase the risk of active phase arrest.

Keywords: Fetus Gender; Labor Curve, Cohort

Copyright $₫$ Iran University of Medical Sciences

Cite this article as: Rashidi Meibodi M, Ghasemi A, Mossayebi E, Afzalzadeh A, Najmi Z, Moradi Y. Normal labor curve is affected by fetus gender: A cohort study. Med J Islam Repub Iran. 2017 (17 Dec);31:93. https://doi.org/10.14196/mjiri.31.93

\section{Introduction}

The number of Cesarean section (CS) has been quadrupled in less than 2 decades (1-3). Some regard CS as a safe and uncomplicated procedure, but it increases the risk of maternal mortality and morbidity (4-6). Previous CS and the diagnosis of nonprogressive labor are 2 major indications for CS (7).

For the first time, in 1954, Friedman showed the normal progress of labor according to parity in different curves (8). Failure to progress in labor was defined as a deviation from these curves. (7). One of the most common causes of CS is the arrest of descent in the second stage of labor. Different factors such as nulliparity, macrosomia, epidural analgesia, hydramnios, hypertensive disorders, gestational diabetes

Corresponding author: Dr Azadeh Afzalzadeh, azaafz@yahoo.com

1. IVF Center, Shahid Akbarabadi Hospital, Iran University of Medical Sciences, Tehran, Iran.

2. Department of Perinatology, Shahid Akbarabadi Hospital, Iran University of Medical Sciences, Tehran, Iran.

3. Minimally Invasive Gynecology, Zanjan University of Medical Sciences, Zanjan, Iran. 4. Pars Advanced and Minimally Invasive Medical Manners Research Center, Pars Hospital, Iran University of Medical Sciences, Tehran, Iran. mellitus, male gender, premature rupture of membranes, and induction of labor were considered as independent risk factors for the arrest of descent in the second stage of labor (9).

In previous studies, male gender has been considered as a risk factor for Cesarean delivery $(7,9,10)$. Some recent studies showed that fetal male gender may affect the progression of labor curve and could be a risk factor for labor arrest in the first and second stages of labor (11). However, data on the labor curve in different fetal genders are limited.

The present investigation aimed at determining the effects of fetus gender on the active phase curve of labor and labor arrest in the first and second stages of labor in Iranian

$\uparrow$ What is "already known" in this topic:

One of the most common causes of CS is the arrest of descent in the second stage of labor. Some studies have shown that male fetal sex may affect the progression of labor curve, and thus could be a risk factor for labor arrest in the first and second stages of labor.

$\rightarrow$ What this article adds:

The present study revealed that active phase stage was slower and longer in women who carried male fetuses compared to those carrying female fetuses; however, fetal sex did not increase the risk of active phase arrest. 
population.

\section{Methods}

In this cohort study, 1550 term (above 37 weeks of gestation) pregnant women, who referred to Shahid Akbar-abadi hospital (affiliated to Iran University of Medical Sciences) and were in the first stage of labor and gave birth between January 2013 and 2014, were enrolled. In this study, convenience sampling method was used to select the participants.

Exclusion criteria were as follow: Previous preterm labor, multiple pregnancy, nonvertex presentation, congenital anomalies, and IUGR (intrauterine growth restriction). All participants were asked to fill informed consent forms before entering the study. The ethics committee of Iran University of Medical Sciences approved this study.

To collect data, we used a check list that included maternal age, BMI, gravidity, and parity. Previous CS, surgical, and medical history of all participants were also recorded. All cases were followed up to delivery. A gynecologist recorded the results of regular cervical examination, dilation, length of labor stages, mode of delivery, sex of fetus, and birth weight of all participants. Cervical dilation was examined every 2 hours and documented in centimeters $(0-10$ $\mathrm{cm})$. To prevent bias (information bias), data collection in this study was done by a trained collector, and all examinations were done by one gynecologist. Our follow- up period was the time in delivery room up to delivery. Moreover, as we explained the study protocol to the participants before recruitment, we had no lost to follow- up. However, 19 patients declined to participate in the study.

The time duration to reach cervical dilatation from 4 to 10 $\mathrm{cm}$ by spontaneous contractions or by augmentation and assessment of labor arrest in the 2 different gender groups were the main outcomes of the study. Secondary outcomes included the assessment of other risk factors of labor arrest or prolongation in the 2 gender groups such as maternal age, BMI, induction, spontaneous rupture of membranes, fetus sex, parity, birth weight, GDM, and anesthesia method. In this analysis, to predict OR (OR Adjusted) between the independent variables and the dependent variable (active phase arrest), we adjusted the maternal age, BMI, labor induction, spontaneous membrane rupture, fetus sex, parity, birth weight, GDM, and epidural anesthesia as independent variables.

\section{Statistical Analysis}

Data were analyzed using SPSS Version 14 (SPSS Inc., Chicago, IL, USA). Student's t test and chi- square test were used to compare continuous and categorical variables. Repeated measures analysis (ANOVA) was utilized to evaluate cervical dilatation overtime. Duration and curves of the first stage of labor were compared between genders. Binary logistic regression analyses with active phase arrest as the dependent variable and maternal age, BMI, labor induction, spontaneous membrane rupture, fetus sex, parity, birth weight, GDM, epidural anesthesia as independent variables were used to assess their relevance for active phase arrest. P-value less than 0.05 was considered as statistically significant.

\section{Results}

In this study, 23 women were excluded based on the exclusion criteria. Finally, 1527 term pregnant women completed the study (Diagram 1). Mean \pm SD age of our study population was $25.5 \pm 5.7$ years and mean \pm SD BMI was $30.4 \pm 4.2 \mathrm{~kg} / \mathrm{m} 2$.

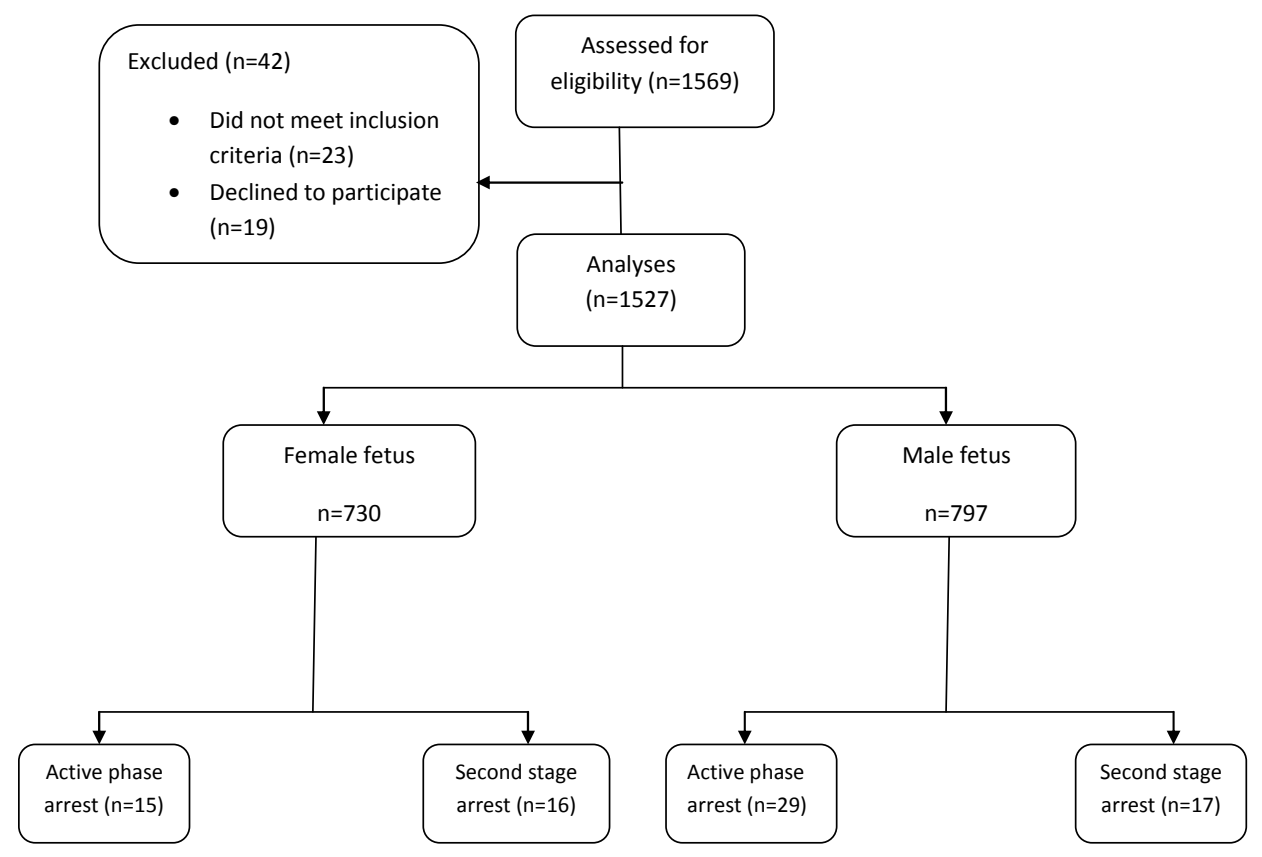

Diagram 1. Flow diagram of participants throughout the study 


\begin{tabular}{|c|c|c|c|}
\hline Variable & Female $(n=730)$ & Male $(n=797)$ & $\mathrm{p}$ \\
\hline Maternal age (year) & $25.6 \pm 5.8$ & $25.4 \pm 5.7$ & 0.4 \\
\hline Maternal BMI $\left(\mathrm{kg} / \mathrm{m}^{2}\right)$ & $29.4 \pm 4.4$ & $29.5 \pm 3.8$ & 0.6 \\
\hline Gravidity (mean) & $1.74 \pm 1.11$ & $1.72 \pm 1.13$ & 0.7 \\
\hline Nulli parous (num\%) & $470(64.4 \%)$ & $511(64.1 \%)$ & 0.9 \\
\hline $\begin{array}{l}\text { History of previous abortion } \\
\text { (num\%) }\end{array}$ & $132(18.1 \%)$ & $121(15.2 \%)$ & 0.13 \\
\hline Labor & & & 0.1 \\
\hline Induction & $369(50.5 \%)$ & $374(46.9 \%)$ & \\
\hline Spontaneous & $361(49.5 \%)$ & $423(53 \%)$ & 0.1 \\
\hline $\begin{array}{l}\text { Spontaneous Rupture of membrane } \\
\text { Anesthesia }\end{array}$ & $288(39.5 \%)$ & $316(39.6 \%)$ & 0.9 \\
\hline Spinal & $56(13.8 \%)$ & $37(8.31 \%)$ & \\
\hline Entonox gas & $277(68.4 \%)$ & $334(75 \%)$ & 0.1 \\
\hline Opium & $72(17.8 \%)$ & $74(16.6 \%)$ & \\
\hline \multicolumn{4}{|l|}{ Mode of delivery } \\
\hline Spontaneous vaginal delivery & $660(90.4 \%)$ & 696(87.3\%) & 0.56 \\
\hline vaginal delivery with vacuum & $6(0.8 \%)$ & $7(0.8 \%)$ & 0.9 \\
\hline vaginal delivery with forceps & $1(0.1 \%)$ & $1(0.1 \%)$ & 0.9 \\
\hline $\mathrm{CS}$ & $63(8.6 \%)$ & $93(11.7 \%)$ & 0.05 \\
\hline Tobacco use, $\%$ & $9(1.2 \%)$ & $11(1.3 \%)$ & 0.8 \\
\hline Hypertension of pregnancy, $\%$ & $47(6.4 \%)$ & $43(5.4 \%)$ & 0.3 \\
\hline Overt Diabetes mellitus\% & $1(0.1 \%)$ & $4(0.5 \%)$ & 0.2 \\
\hline Gestational diabetes mellitus & $49(6.7 \%)$ & $41(5.1 \%)$ & 0.1 \\
\hline Birthweight,(g) & $3154.5 \pm 447$ & $3270.7 \pm 420$ & 0.00 \\
\hline Birthweight $>4000 \mathrm{~g}$ & $18(2.4 \%)$ & $25(3.1 \%)$ & 0.4 \\
\hline Apgar 1th min(median) & 9 & 9 & 0.1 \\
\hline Apgar $5^{\text {th }}$ min (median) & 10 & 10 & 0.1 \\
\hline \multicolumn{4}{|l|}{ Indications for cesarean de } \\
\hline Par. & Female $(n=730)$ & Male $(n=797)$ & $\mathrm{p}$ \\
\hline Cord prolapse & $1(1.6 \%)^{*}$ & 0 & 0.2 \\
\hline Second stage arrest & $16(25.4 \%)$ & $17(18.3 \%)$ & 0.2 \\
\hline Active phase arrest & $15(23.8 \%)$ & $29(31.2 \%)$ & 0.4 \\
\hline Thick meconium & $20(30.3 \%)$ & $17(17.7 \%)$ & 0.08 \\
\hline Fetal distress & $14(21.2 \%)$ & $33(34.4 \%)$ & 0.08 \\
\hline
\end{tabular}

In this study, 730 neonates were female $(47.8 \%)$ and $797(52.1 \%)$ were male. Induction of labor was performed in $743(48.7 \%)$, and spontaneous rupture of membranes was present in 604 cases $(39.6 \%)$ at admission. Characteristics of the study population are demonstrated in Table 1. Except for the birth weight, which was significantly different between male and female groups, other variables were comparable between the 2 groups (Table 1).

Thick meconium followed by second stage arrest were the most common reasons for CS in female fetuses, and fetal distress followed by active phase arrest were the most common reasons for CS in male fetuses (Table 2).

Except for mean duration from full dilatation up to deliv-

Table 3. Labor progression in different fetal gender groups

\begin{tabular}{|c|c|c|c|}
\hline Time duration & Female $(n=730)$ & Male $(n=797)$ & $\mathrm{p}$ \\
\hline Mean duration from beginning of active phase up to full dilatation & $2.47 \pm 1.6$ & $3.4 \pm 1.8$ & $<0.001$ \\
\hline Mean duration from full dilatation up to delivery & $0.5 \pm 0.7$ & $0.5 \pm 1$ & 0.3 \\
\hline Duration of time from dilatation $4 \mathrm{~cm}$ to $6 \mathrm{~cm}$ & $1.4 \pm 0.9$ & $1.7 \pm 1.1$ & $<0.001$ \\
\hline Duration of time from dilatation $6 \mathrm{~cm}$ to $8 \mathrm{~cm}$ & $0.8 \pm 0.6$ & $0.9 \pm 0.7$ & 0.002 \\
\hline Duration of time from dilatation $8 \mathrm{~cm}$ to $10 \mathrm{~cm}$ & $0.6 \pm 0.4$ & $0.7 \pm 0.5$ & 0.001 \\
\hline
\end{tabular}

Labor curves by fetal gender

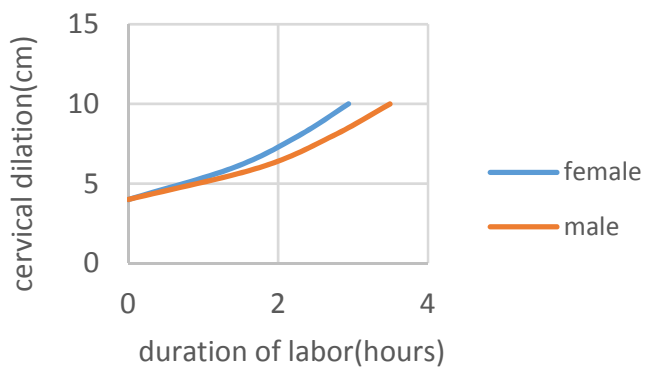

Fig. 1. Labor Curves in Male and Famele Fetuses 


\begin{tabular}{lccc} 
Table 4. Labor progression in different fetal gender groups, considering parity & & \\
\hline Time duration & Female $(\mathrm{n}=730)$ & Male $(\mathrm{n}=797)$ & $\mathrm{p}$ \\
\hline Duration of time from dilatation $4 \mathrm{~cm}$ to $6 \mathrm{~cm}$ & & & \\
Nulliparity & $1.5 \pm 0.9$ & $1.1 \pm 0.8$ & $<0.001$ \\
Multiparity & $1.9 \pm 1.1$ & $1.4 \pm 1.1$ & $<0.001$ \\
Duration of time from dilatation $6 \mathrm{~cm}$ to $8 \mathrm{~cm}$ & & $1.1 \pm 0.7$ & 0.03 \\
Nulliparity & $1 \pm 0.7$ & $0.7 \pm 0.6$ & 0.005 \\
Multiparity & $0.6 \pm 0.4$ & & \\
Duration of time from dilatation $8 \mathrm{~cm}$ to $10 \mathrm{~cm}$ & & $0.8 \pm 0.5$ & 0.009 \\
Nulliparity & $0.7 \pm 0.5$ & $0.5 \pm 0.4$ & 0.01 \\
Multiparity & $0.4 \pm 0.3$ &
\end{tabular}

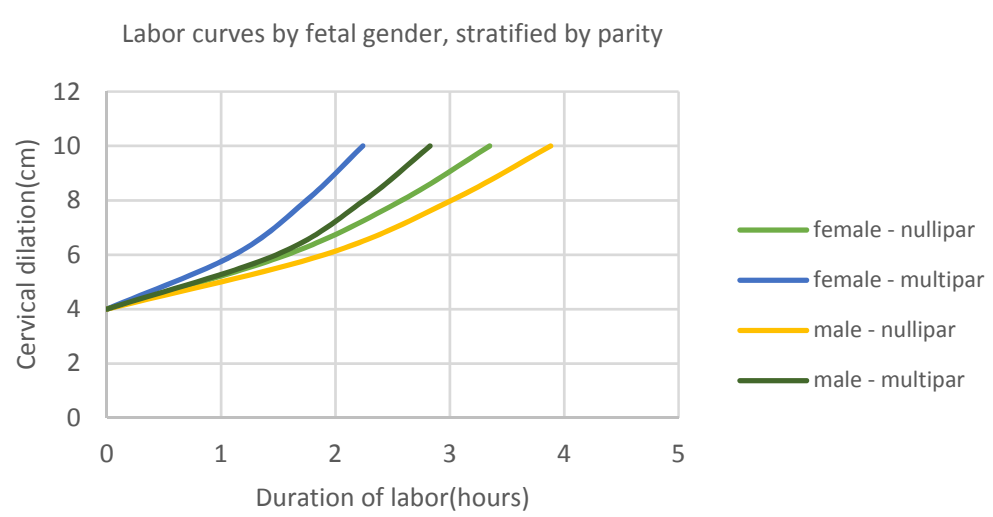

Fig. 2. Labor curves by fetal gender, stratified by parity

Table 5. Binary logistic regression analysis by considering active phase arrest as dependent variable

\begin{tabular}{|c|c|c|c|c|c|}
\hline \multirow[t]{2}{*}{ Variable } & \multirow[t]{2}{*}{ OR Unadjusted } & \multirow[t]{2}{*}{ OR Adjusted } & \multicolumn{2}{|c|}{ CI 95\% } & \multirow[t]{2}{*}{$\mathrm{p}$} \\
\hline & & & Lower & Upper & \\
\hline Maternal age & 1.07 & 0.937 & 0.841 & 0.235 & 0.235 \\
\hline BMI & 1.01 & 0.992 & 0.887 & 0.884 & 0.884 \\
\hline Induction & 1.7 & 1.180 & 0.399 & 0.765 & 0.765 \\
\hline Spontaneous rupture of membranes & 0.7 & 0.693 & 0.220 & 0.530 & 0.530 \\
\hline Fetus sex & 0.7 & 1.18 & 1.012 & 0.031 & 0.031 \\
\hline Nulliparity & 2.2 & 0.263 & 0.067 & 0.056 & 0.056 \\
\hline Birth weight & 1.001 & 0.999 & 0.998 & 0.171 & 0.171 \\
\hline GDM & 1 & 1.346 & 0.444 & 0.599 & 0.599 \\
\hline
\end{tabular}

ery (second stage) $(\mathrm{p}=0.35)$, all other times were significantly longer in male sex gender group (Table 3, Fig. 1). All durations were also significantly different when parity was considered (Table 4, Fig. 2) $(\mathrm{p}<0.05)$

By considering maternal age, BMI, induction, spontaneous rupture of membranes, fetus sex, parity, birth weight, GDM, and anesthesia method as independent variables and active phase arrest as a dependent variable, we found that maternal age and BMI, induction, parity, birth weight, and regional anesthesia were independent risk factors for active phase arrest. However, we could not show fetal sex as an independent risk factor (Table 5).

\section{Discussion}

The results of the present study revealed that the first stage of labor was slower in women with male fetuses than those who carried female fetuses (Mean duration in female fetuses was 2.4 and it was 3.4 in male fetuses). This finding was compatible with that of Cahill et al. In their study, median duration of time for dilatation from 4 to $10 \mathrm{~cm}$ was 4 hours in the female group and 4.6 hours in the male group (11). In a retrospective cohort study, Sheiner et al. found that the risk of active phase arrest and command for CS were $20 \%$ higher in women who carried male fetuses (3). In another cohort study, Melamed et al. reported $20 \%$ more $\mathrm{CS}$ risk in women with male fetuses than those with female fetuses (12).

These findings demonstrated the important role of the fetus not just for labor initiation, but also for process of labor. The hypothesis for increased risk of CS in male fetuses was macrosomia in such fetuses (11). Our results revealed that mean birth weight was significantly higher in male neonates than female ones, which confirms the potential role of macrosomia.

In Cahil et al. study, maternal age, BMI, rate of induction, and spontaneous rupture of membranes, parity, gravidity, addiction, rate of maternal HTN, and GDM were not significantly different between male and female groups, while the rate of vaginal delivery with and without device was significantly different in their study, and rate of CS was higher in the male group.

Our findings also revealed a higher rate of CS in male sex fetuses. Moreover, we found that fetal distress and thick meconium were the most common reasons for CS in the 
male and female groups, respectively.

Eogan et al. evaluated 4070 male fetuses and 4005 female neonates, retrospectively, and found that epidural anesthesia, duration of labor, delivery with forceps, and CS delivery were significantly higher in the male group (13).

Lieberman et al. evaluated 2439 nullipar women and found that CS rate was $13.2 \%$ in the male group and $9.6 \%$ in the female group. Fetal distress was the reason for CS in $70 \%$ of CS deliveries, and failure to progress was the reason for CS in $30 \%$. In their study, male gender was an independent predictor of fetal distress $(\mathrm{OR}=2.2)(14)$. However, in the present study, gender was not a predictor of active phase arrest when different factors were considered.

Feinstein et al. evaluated 93266 singletons pregnancies and investigated nulliparity, birth weight, HTN, GDM, male gender, premature rupture of membranes, and induction of labor as predictors of labor arrest. Nonetheless, in the current study, fetus gender, GDM, and spontaneous rupture of membranes were not predictors of labor arrest.

The curves revealed that duration to reach full dilatation was longer for women who carried male fetuses. Considering parity, we found that the least duration of active phase was for multiparous women who carried female fetuses, and the longest duration was for nulliparous women who carried male fetuses. These findings are compatible with those of Cahill et al. (11).

Duration of active phase is longer in male fetuses, but is does not lead to more active phase arrest, as we found that the rate was similar between the 2 sex groups. This slower progression may be caused by higher birth weight in male fetuses.

Our main limitation in this study was small sample size. Moreover, in the present study, we included a heterogeneous population of patients with different parity, gravidity, and BMI, which possibly had a profound impact on the validity of the scientific conclusions. On the other hand, labor curve duration was variable among different ethnicities, which would limit the generalizability of our results. We recommend conducting further studies with a larger and more homogenous sample size and in different populations to evaluate the effect of fetal gender on labor progression.

\section{Conclusion}

Active phase stage was slower and longer in women who carried male fetuses compared to those carrying female fetuses; however, fetal sex did not increase the risk of active phase arrest. Moreover, duration of the second stage was not different in the 2 groups.

\section{Conflict of Interests}

The authors declare that they have no competing interests.

\section{References}

1. Wu Wl. Cesarean delivery in Shantou, China: a retrospective analysis of 1922 women. Birth. 2000;27(2):86-90.

2. Bulger T, Howden-Chapman P, Stone P. A cut above: the rising Caesarean section rate in New Zealand. $\mathrm{N} Z$ Med $J$. 1998;111(1059):30-3

3. Sheiner E, Shoham-Vardi I, Hershkovitz R, Katz M, Mazor M. Infertility treatment is an independent risk factor for cesarean section among nulliparous women aged 40 and above. Am J Obstet Gynecol 2001;185(4):888-92.

4. Lydon-Rochelle M, Holt VL, Easterling TR, Martin DP. Risk of uterine rupture during labor among women with a prior cesarean delivery. $\mathrm{N}$ Engl J Med . 2001;345(1):3-8.

5. Chaim W, Bashiri A, Bar-David J, Shoham-Vardi I, Mazor M. Prevalence and clinical significance of postpartum endometritis and wound infection. Infect Dis Obstet Gynecol. 2000;8(2):77-82.

6. Srp B, Velebil P. Proportion of caesarean sections and main causes of maternal mortality during 1978-1997 in the Czech Republic. Ceska gynekologie/Ceska lekarska spolecnost J Ev Purkyne. 1999; 64(4):21923 .

7. Sheiner E LA, Feinstein U, Hallak M, Mazor M. Risk factors and outcome of failure to progress during the first stage of labor: a population-based study. Acta Obstet Gynecol Scand. 2002;81(3):2226.

8. Friedman E. The graphic analysis of labor. Am J Obstet Gynecol. 1954;68(6):1568-75.

9. Feinstein U, Sheiner E, Levy A, Hallak M, Mazor M. Risk factors for arrest of descent during the second stage of labor. Int J Gynecol Obstet. 2002;77(1):7-14.

10. Di Renzo GC, Rosati A, Sarti RD, Cruciani L, Cutuli AM. Does fetal sex affect pregnancy outcome? Gender med. 2007;4(1):19-30.

11. Cahill AG, Roehl KA, Odibo AO, Zhao Q, Macones GA. Impact of fetal gender on the labor curve. Am J Obstet Gynecol. 2012;206(4):335. e1-e5.

12. Melamed N, Yogev Y, Glezerman M. Fetal gender and pregnancy outcome. J Matern Fetal Neonatal Med. 2010;23(4):338-44.

13. Eogan MA, Geary MP, O'Connell MP, Keane DP. Effect of fetal sex on labour and delivery: retrospective review. BMJ. 2003;326(7381): 137.

14. Lieberman E, Lang JM, Cohen AP, Frigoletto FD, Acker D, Rao R. The association of fetal sex with the rate of cesarean section. Am J Obstet Gynecol. 1997;176(3):667-71. 